RESEARCH PAPER

\title{
Smoke-free cafe in an unregulated European city: highly welcomed and economically successful
}

\author{
N Künzli, P Mazzoletti, M Adam, T Götschi, P Mathys, C Monn, O Brändli
}

Tobacco Control 2003;12:282-288

See end of article for authors' affiliations

.....................

Correspondence to: Professor Nino Künzli, MD $\mathrm{PhD}$, University of Southern California, Keck School of Medicine, Division of Occupational and Environmental Health 1540 Alcazar Street, CHP 236, Los Angeles, CA 90033, USA;

Kuenzli@usc.edu

Received

20 January 2003

Accepted 27 June 2003

\begin{abstract}
Objective: In a unique setting with two identical cafes, which only differed in their smoking ordinances, this study assessed the influence of smoking policies on the choice of the cafe, investigated regulatory preferences among customers, and evaluated the claim that smoking cafes have better sales performance in a city without smoking bans.

Methods: In a parallel assessment, customers of both cafes answered a questionnaire. Sales were compared and air pollutants were measured to confirm air quality differences.

Results: The two customer groups $(n=177)$ differed only with regard to smoking status $(p<0.01)$. The smoking regulation was the most often cited selection criterion $(83 \%)$. In the non-smoking café, $89 \%$ indicated that they were usually annoyed by smoke in coffee houses, and $62 \%$ would avoid or leave cafes for this reason. Two thirds stated that all cafe/restaurants should offer the opportunity of a smoke-free environment. However, almost half stated that mandatory regulations are not needed and that customers should make individual arrangements based on tolerance and courtesy. Those who were informed about the health effects of secondhand smoke were more likely to call for clear policies. Whereas sales showed no differences, tips were $22 \%(p<0.001)$ higher in the non-smoking cafe. Conclusion: In a generation raised in smoking friendly environments, customers paradoxically ask for a landmark shift towards smoke-free opportunities, while substantially adhering to the tobacco industry paradigm of promoting "tolerance" rather than smoke-free policies. Given the clear preference of a large number of customers, hospitality businesses could, however, greatly profit from offering smokefree environments even in the absence of regulatory policies.
\end{abstract}

n contrast to the USA, smoke-free public areas are still rare in Switzerland as in most European countries. In particular, in the hospitality business such as restaurants, coffee houses, or bars, smoking is very prevalent and expected to be accepted by the customers. Given that the majority of the population are non-smokers, this situation may be of surprise. It reflects, however, the smoking friendly environment where non-smoking regulations are harshly opposed by the tobacco industry. Lee and colleagues ${ }^{1}$ showed that stakeholders were particularly successful in influencing policy making and public opinion, with the industry having been a member of the Swiss Federal Tobacco Commission ${ }^{2}$ for decades. With 34\% smokers, Switzerland belongs to the group of European countries with a high smoking prevalence, and the annual per capita cigarette consumption ( $>2700$ cigarettes) is surpassed only in Greece, Hungary, and Slovenia. ${ }^{34}$ Federal regulations are weak, requiring the employer to protect non-smokers from the annoyance of smoke "if the circumstances offer such opportunities", while more stringent specifications are the responsibility of the local county governments. Accordingly, regulations in the hospitality business differ across the 26 counties.

The general pattern of Swiss policies, thus, can be described as conservative, driven by the attempt to meet the smokers' needs rather than to promote smoke-free environments. The usual policy parlance is to require "appropriate smoking bans, if feasible". ${ }^{\prime}$ This situation leaves room to debate what is appropriate and feasible, and the tobacco industry's lobbying emphasising that the majority would not want smoking bans. ${ }^{5-7}$ Globally, the industry has co-opted and manipulated the hospitality business to prevent and oppose smoke-free restaurants. ${ }^{18}$ A current campaign of these two partners follows the same strategy in Switzerland (http:// www.toleranz-lebensfreude.ch). To prevent smoking regulations in restaurants, "friendly agreements" between customers, "tolerance", and "courtesy" are offered to "free citizens" as alternatives to clear policies and bans that would protect public health.

The tobacco industry bases its partnership with the hospitality business on the argument that smoking bans would damage economic performance. ${ }^{89}$ It has been shown that city wide smoking ban policies for restaurants have no influence on sales. ${ }^{9}$ These studies are summarised in a report available on the internet (<http://www.vctc.org.au/publ/ reports/Hospitality_paper_summary.pdf $>$ by Scollo and Lal), and in a slide presentation by Hyland $(<$ http:// tc.bmjjournals.com/cgi/content/full/1//3/DCl $>$ ). The evidence, however, stems from city or county wide ordinances, and thus cannot be generalised to the current situation in many countries, where general bans have not been set. ${ }^{9-11}$ In an unregulated market, one may continue to argue that non-smoking restaurants are disadvantaged if the next door facility has no restrictions. Given that different restaurants and their customers may be incomparable groups in many regards, a direct assessment of these claims is usually not possible, and controlled intervention studies are unrealistic. We conducted a study that directly assessed the influence of smoking policies on a single facility, in an unregulated environment. We used the opportunity of a unique "controlled experimental setting" to investigate the evidence for "common sense" beliefs.

In the centre of the city of Basel, the second largest city in Switzerland, an innovative hospitality business was initiated a few years ago. Among other activities, the "Unternehmen Mitte" runs two identical cafes which only differ in their smoking policies (fig 1). Accordingly, we hypothesised that unlike in any other hospitality business the customers of the two cafes may represent samples of the same target population, having a unique free choice between two options 


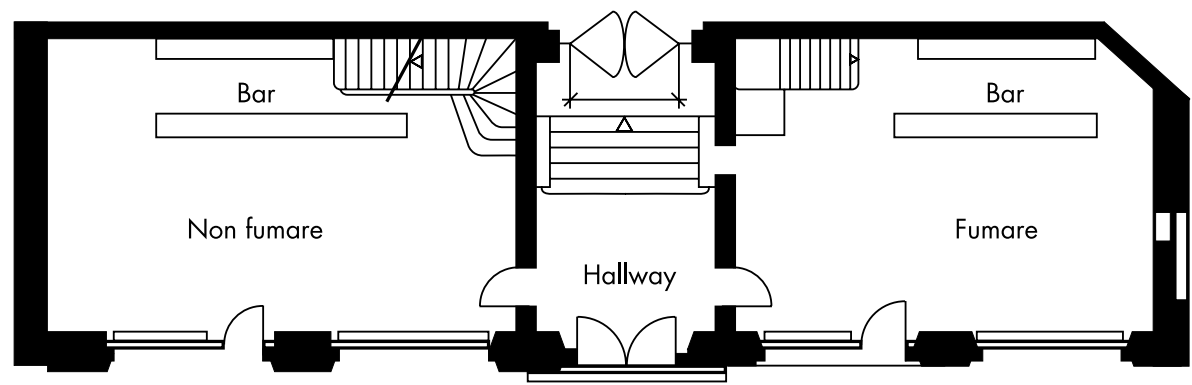

Figure 1 The plan of the identical cafes, one allowing smoking and one not. The front window doors are open only in the warm season.

that differ only in their smoking policy. We used this population to assess the motivations to choose one or the other cafe, to investigate regulatory preferences and attitudes toward non-smoking policies, and to evaluate claims that smoking cafes have better sales performances and that smokers leave higher tips. To confirm air quality differences between the two cafes, we also measured air pollutants.

\section{METHODS}

Located to the left and right side of the entrance hallway, the two cafes both face the main pedestrian street, with a large window facade to the front (fig 1). Appearance, style (architecture, furniture, lights), menus, service, and prices are entirely identical in both. The only distinction consists in the smoking policies, which are declared: the cafe on the left side is called non fumare (non-smoking), offering 32 seats; the one on the right side is called fumare (smoking) with 34 seats.
Although a Swiss German speaking city, these Italian terms are very well understood and communicate at the same time the smoking policy and the Italian style of the cafes.

To maximise comparability of data all observations and measurements described below (questionnaires, economics, air quality) were taken simultaneously in the fumare and non fumare. Additionally, to optimise the experimental condition, data were only collected between 8 am and $6 \mathrm{pm}$ and during cold or rainy weather. In evening hours, the fumare has to be considered a bar rather than a cafe, with the non fumare having limited business hours in the evening. During the warm season, customers can also sit outside at the boardwalk where no smoking policies exist, thus disrupting the experimental setting. The study was conducted in spring 2002.

The main part of our study consisted of a survey of clients in both cafes. During the investigation the two interviewers visited the locations simultaneously. Investigation periods

\begin{tabular}{|c|c|c|c|c|c|c|c|}
\hline \multirow[b]{2}{*}{ Question } & \multicolumn{2}{|c|}{ Fumare } & \multicolumn{2}{|c|}{ Non fumare } & \multicolumn{2}{|l|}{ Total } & \multirow[b]{2}{*}{$\mathrm{p}$ Value } \\
\hline & $\bar{n}$ & $\%$ & $n$ & $\%$ & $\bar{n}$ & $\%$ & \\
\hline \multicolumn{8}{|l|}{ Participation } \\
\hline Yes & 87 & 75.0 & 90 & 76.9 & 177 & 76.0 & 0.73 \\
\hline \multicolumn{8}{|l|}{ Sex } \\
\hline Female & 50 & 57.5 & 57 & 63.3 & 107 & 60.5 & 0.43 \\
\hline \multicolumn{8}{|l|}{ Age (years) } \\
\hline$\leqslant 20$ & 9 & 10.3 & 3 & 3.3 & 12 & 6.8 & 0.14 \\
\hline$>20-30$ & 33 & 37.9 & 26 & 28.9 & 59 & 33.3 & \\
\hline$>30-40$ & 26 & 29.9 & 36 & 40 & 62 & 35 & \\
\hline$>40-50$ & 13 & 14.9 & 20 & 22.2 & 33 & 18.6 & \\
\hline$>50$ & 6 & 6.9 & 5 & 5.6 & 11 & 6.2 & \\
\hline \multicolumn{8}{|l|}{ Education } \\
\hline Up to high school & 5 & 5.8 & 2 & 2.2 & 7 & 4.0 & 0.25 \\
\hline College or professional degree & 31 & 35.6 & 26 & 28.9 & 57 & 32.2 & \\
\hline Higher degrees or university & 51 & 58.6 & 62 & 68.9 & 113 & 63.8 & \\
\hline \multicolumn{8}{|l|}{ Came in the company of others } \\
\hline Yes & 54 & 62.1 & 48 & 53.3 & 102 & 57.6 & 0.24 \\
\hline \multicolumn{8}{|l|}{ Smoking status } \\
\hline Non-smoker & 8 & 9.2 & 53 & 58.9 & 61 & 34.5 & $<0.01$ \\
\hline Ex-smoker & 2 & 2.3 & 19 & 21.1 & 21 & 11.9 & \\
\hline Smoker & 77 & 88.5 & 18 & 20.0 & 95 & 53.7 & \\
\hline \multicolumn{8}{|c|}{ "Does passive smoking increase the risk of dying from lung cancer" } \\
\hline Yes & 47 & 54.0 & 61 & 67.8 & 108 & 61.0 & 0.15 \\
\hline No & 22 & 25.3 & 14 & 15.6 & 36 & 20.3 & \\
\hline Don't know & 18 & 20.7 & 15 & 16.7 & 33 & 18.6 & \\
\hline \multicolumn{8}{|l|}{ Time spent in cafe } \\
\hline$\leqslant 30$ mins & 35 & 40.2 & 32 & 35.6 & 67 & 37.9 & 0.88 \\
\hline$>30-60$ mins & 32 & 36.8 & 33 & 36.7 & 65 & 36.7 & \\
\hline$>60$ mins & 9 & 10.3 & 12 & 13.3 & 21 & 11.9 & \\
\hline No statement & 11 & 12.6 & 13 & 14.4 & 24 & 13.6 & \\
\hline
\end{tabular}


Table 2 Customer perceptions and expectations about smoking policies in the hospitality business in Basel $(n=177)$

\begin{tabular}{|c|c|c|c|c|c|c|c|}
\hline \multirow[b]{2}{*}{ Question } & \multicolumn{2}{|c|}{ Fumare } & \multicolumn{2}{|c|}{ Non fumare } & \multicolumn{2}{|c|}{ Total } & \multirow[b]{2}{*}{$\mathrm{p}$ Value } \\
\hline & $\mathrm{n}$ & $\%$ & $\mathrm{n}$ & $\%$ & $\mathrm{n}$ & $\%$ & \\
\hline \multicolumn{8}{|c|}{ "What is your experience concerning the availability of smoke-free tables in cafes" } \\
\hline Too many & 4 & 4.6 & 0 & 0.0 & 4 & 2.3 & $<0.01$ \\
\hline Sufficient & 29 & 33.3 & 19 & 21.1 & 48 & 27.1 & \\
\hline Insufficient & 10 & 11.5 & 53 & 58.9 & 63 & 35.6 & \\
\hline Don't know & 44 & 50.6 & 18 & 20.0 & 62 & 35.0 & \\
\hline \multicolumn{8}{|c|}{ "What future opportunities would you like to have in cafes" } \\
\hline More or only smoking zones & 5 & 5.8 & 3 & 3.3 & 8 & 4.5 & $<0.01$ \\
\hline In equal parts & 58 & 66.7 & 40 & 44.4 & 98 & 55.4 & \\
\hline More or only non-smoking zones & 13 & 14.9 & 42 & 47.7 & 55 & 31.1 & \\
\hline Don't know & 11 & 12.6 & 5 & 5.6 & 16 & 9.0 & \\
\hline \multicolumn{8}{|c|}{ "Do you feel irritated by cigarette smoke in cafes" } \\
\hline Yes* & 35 & 40.2 & 80 & 88.9 & 115 & 65.0 & $<0.01$ \\
\hline No & 50 & 57.5 & 10 & 11.1 & 60 & 33.9 & \\
\hline Don't know & 2 & 2.3 & 0 & 0.0 & 2 & 1.1 & \\
\hline \multicolumn{8}{|c|}{ "Have you ever left or avoided cafes due to cigarette smoke" } \\
\hline Yest & 21 & 24.1 & 56 & 62.2 & 77 & 43.5 & $<0.01$ \\
\hline Noł & 60 & 69.0 & 33 & 36.7 & 93 & 52.5 & \\
\hline Don't know & 6 & 6.9 & 1 & 1.1 & 7 & 4.0 & \\
\hline \multicolumn{8}{|c|}{ "Have you ever left or avoided cafes due to a ban on smoking" } \\
\hline Yest & 45 & 51.7 & 10 & 11.1 & 55 & 31.1 & $<0.01$ \\
\hline Noł & 36 & 41.4 & 74 & 82.2 & 110 & 62.1 & \\
\hline Don't know & 6 & 6.9 & 6 & 6.7 & 12 & 6.8 & \\
\hline \multicolumn{8}{|c|}{ "Smoke-free consumption should be possible in all restaurants/cafes" } \\
\hline Yes§ & 56 & 64.4 & 74 & 82.2 & 130 & 73.4 & 0.02 \\
\hline NoI & 21 & 24.1 & 13 & 14.4 & 34 & 19.2 & \\
\hline Don't know & 10 & 11.5 & 3 & 3.3 & 13 & 7.3 & \\
\hline \multicolumn{8}{|c|}{ "The simultaneous presence of smokers and non-smokers is a problem" } \\
\hline Yes $\S$ & 29 & 33.3 & 37 & 41.1 & 66 & 37.3 & 0.47 \\
\hline Nol & 48 & 55.2 & 46 & 51.1 & 94 & 53.1 & \\
\hline Don't know & 10 & 11.5 & 7 & 7.8 & 17 & 9.6 & \\
\hline
\end{tabular}

were usually restricted to one hour, during which all customers were asked to participate, giving a short introduction of the general aim (to investigate the opinions of customers) and told they would receive a consumer voucher. Participants received the questionnaire and a pen for self administration. All customers were advised to fill in the questionnaire completely and on their own, without discussion with their colleagues. Before moving to the next table, the interviewers remained available for a couple of minutes for any needed clarification and to ascertain that answers were given independently. To control for the influence of the interviewer, they regularly changed between the cafes, on a predetermined schedule.

An economic comparison was made using the concurrent cashier data and the tips covering the periods of our questionnaire assessment. Given the lack of per capita sales information, we estimated a per capita sales index, with the hourly sales in the nominator and an average hourly count of customers in the denominator. These counts were based on 51 repeated cross-sectional counts of all customers present in the cafes, conducted on the hour, for eight days. To compare sales of this short period with a more representative time, we had access to cashier data of one six-month winter period (October 2000 to March 2001). On five of the eight sales assessment days, tips were counted over the daytime period. We compared the absolute tips, the tips per capita (same indexed denominator as above), and the tips in per cent of the same day sales across the two cafés, respectively ( 8 am to $6 \mathrm{pm}$ ).
The air hygiene assessment was conducted indoors (fumare, non fumare) and outdoors during daytime. For practical reasons, the measurement days started a few days before the query. We measured mass concentrations of fine particulate matter $\left(\mathrm{PM}_{25}\right)$, chemical elements on these fine particles, nitrogen dioxides $\left(\mathrm{NO}_{2}\right)$ (passive samplers), and volatile organic compounds (VOC passive samplers), using the same equipment, laboratories, and protocols used in our previous studies. ${ }^{12-15} \mathrm{We}$ used $\chi^{2}$ statistics to compare distributions in answers from the two customer groups. Multivariate logistic regressions were used to investigate predictors of answer patterns.

\section{RESULTS}

The study population $(\mathrm{n}=77)$ is described in table 1 . In both cafes, participation was similar $(76 \%)$. Reasons for nonparticipation were mostly lack of time ( $12 \%)$ or interest ( $10 \%)$. The customers of the two places did not differ with regard to any sociodemographic characteristic or knowledge about the health relevance of secondhand smoke, nor was there any difference in the distribution of the time spent in the cafe. The only difference between the two customer groups related to smoking status.

We asked for reasons for choosing one or the other cafe. A total of 13 items were offered (plus "others"), covering smoking regulation, odour, health concerns, ambiance, service, or meeting someone. In both groups, the smoking regulation was by far the most often cited selection criterion $(83 \%)$. A total of $43.8 \%(\mathrm{p}<0.01)$ of non fumare customers made their choice 
Table 3 Answers of customers to statements regarding policy options, $(n=177)$

\begin{tabular}{|c|c|c|c|c|c|c|c|}
\hline \multirow[b]{2}{*}{ Question } & \multicolumn{2}{|c|}{ Fumare } & \multicolumn{2}{|c|}{ Non fumare } & \multicolumn{2}{|c|}{ Total } & \multirow[b]{2}{*}{$\mathrm{p}$ Value } \\
\hline & $\mathrm{n}$ & $\%$ & $\mathrm{n}$ & $\%$ & $\mathrm{n}$ & $\%$ & \\
\hline
\end{tabular}

"Is a spatial separation of smoking and non-smoking sections in a cafe reasonable?"

$\begin{array}{rrrrrrrr}\text { Yes } & 68 & 78.2 & 76 & 84.4 & 144 & 81.4 & 0.56 \\ \text { No } & 12 & 13.8 & 9 & 10.0 & 21 & 11.9 & \end{array}$

$\begin{array}{lrrrrrr}\text { No } & 12 & 13.8 & 9 & 10.0 & 21 & 11.9\end{array}$

"Would you favour a temporal ban on smoking in cafes ( 8 am to $5 \mathrm{pm})$ ?"

$\begin{array}{llllllll}\text { Yes } & 7 & 8.0 & 22 & 24.4 & 29 & 16.4 & 0.01\end{array}$

$\begin{array}{lllllrr}\text { No } & 75 & 86.2 & 59 & 65.6 & 134 & 75.7\end{array}$

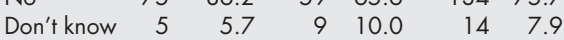

"No regulations are necessary. The customers should make individual arrangements with tolerance and courtesy"

$\begin{array}{lrrrrrrr}\text { Yes }^{\S} & 48 & 55.2 & 37 & 41.1 & 85 & 48.0 & 0.15 \\ \text { Noף } & 30 & 34.5 & 43 & 47.8 & 73 & 41.2 & \\ \text { Don't know } & 9 & 10.3 & 10 & 11.1 & 19 & 10.7 & \end{array}$

"Regulations for smoking/non-smoking sections are the reponsibility of the cafe owner"

$\begin{array}{lrrrrrrr}\text { Yes§ } & 54 & 62.1 & 47 & 52.2 & 101 & 57.1 & 0.09 \\ \text { Noף } & 21 & 24.1 & 35 & 38.9 & 56 & 31.6 & \\ \text { Don't know } & 12 & 13.8 & 8 & 8.9 & 20 & 11.3 & \end{array}$

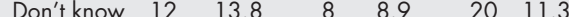

"There is a need for mandatory smoking/non-smoking regulations to

be able to consume in a smoke-free environment"

$\begin{array}{llllllll}\text { Yes§ } & 20 & 23.0 & 43 & 47.8 & 63 & 35.6 & <0.01 \\ \text { Noף } & 54 & 62.1 & 36 & 40.0 & 90 & 50.8 & \end{array}$

$\begin{array}{lllllll}\text { Don't know } & 13 & 14.9 & 11 & 122 & 24 & 13.6\end{array}$

$\S$ Absolutely true or mostly true; đabsolutely wrong or mostly wrong.

because of odour annoyance, and $13.8 \%(p=0.05)$ chose non fumare for health concerns. Meeting someone was indicated by $31.9 \%$ of fumare visitors, but only $12.5 \%$ of the non fumare customers $(p=0.05)$. Otherwise customer's perception of the two cafes confirmed the experimental setting of identical options.

We also analysed the determinants of the cafe selection in a multivariate model. The visitors' smoking status was by far the strongest predictor of choice (odds ratio (OR) 66.2, 95\% confidence interval (CI) 20.8 to 210.1). Meeting someone was 3.8 times more likely (95\% CI 1.0 to 14.5 ) among fumare customers.

A total of $15.3 \%(n=27)$ of all clients chose the cafe that does not correspond to their smoking status. Among smokers, the only multivariate determinant of choosing the non fumare was the time of the day. Smokers preferred the non fumare in the morning hours from 8 am to midday (OR 4.4, 95\% CI 1.1

Table 4 Concentrations in the three micro-environments $\left(\mu \mathrm{g} / \mathrm{m}^{3}\right), \mathrm{n}\left(\mathrm{PM}_{2.5}\right)=4 ; \mathrm{n}\left(\mathrm{NO}_{2}\right)=3 ; \mathrm{n}(\mathrm{VOC})=2$

\begin{tabular}{|c|c|c|c|c|c|c|}
\hline \multirow[b]{2}{*}{ Air pollutant } & \multicolumn{2}{|c|}{ Fumare } & \multicolumn{2}{|c|}{ Non fumare } & \multicolumn{2}{|c|}{ Outdoor } \\
\hline & $A M$ & ASD & AM & ASD & $A M$ & ASD \\
\hline $\mathrm{PM}_{2.5}$ & 163.8 & 32.2 & 36.2 & 11.8 & 10.7 & 3.9 \\
\hline $\mathrm{NO}_{2}$ & 49.0 & 2.2 & 41 & 4.5 & 33.6 & 0.6 \\
\hline \multicolumn{7}{|l|}{ VOC } \\
\hline Benzene & 3.0 & 0.3 & 0.9 & 0.1 & 0.8 & 0.0 \\
\hline Tolvene & 9.9 & 0.3 & 4.3 & 1.0 & 4.5 & 0.5 \\
\hline Ethylbenzene & 1.3 & 0.1 & 0.6 & 0.1 & 0.6 & 0.0 \\
\hline $\mathrm{m} / \mathrm{p}$-xylene & 4.0 & 0.2 & 1.8 & 0.3 & 1.8 & 0.2 \\
\hline o-xylene & 1.2 & 0.0 & 0.6 & 0.1 & 0.6 & 0.1 \\
\hline Styrene & 1.2 & 0.3 & 0.2 & 0.0 & 0.1 & 0.0 \\
\hline
\end{tabular}

$\mathrm{AM}$, arithmetic mean; ASD, arithmetic standard deviation; VOC volatile organic compounds to 16.5). The only significant reason for non-smokers visiting the smoking part were appointments with others (OR 7, 95\% CI 1.0 to 49.3). Models included "sex", "age", "education", "being in the company of others", "meeting someone", and "smoking policy".

Table 2 summarises the customer's perception and expectations regarding smoking policies in other cafes in Basel. As expected, the answers were significantly different among the two visitor groups. However, it is of note that even among the customers of the fumare, large fractions agreed that the current situation is not optimal. Specifically, $82 \%$ of the fumare visitors indicated that at least as many non-smoking zones should be offered as smoking zones. A high percentage of the non fumare customers expressed annoyance from tobacco smoking in cafes (89\% "somewhat", "relatively strong" or "very strong" annoyance). A total of $62 \%$ indicated that they "sometimes", "regularly" or "always" avoided cafes because of tobacco smoke.

Two thirds of all customers supported the statement that every restaurant should also offer the option of a smoke-free consumption. Only a third in both cafes believed that the simultaneous presence of smokers and non-smokers was a problem.

The two customer groups' attitudes toward smoking regulations in restaurants (table 3 ) showed that most preferred separate rooms $(81 \%)$. A temporary smoking ban during the daytime had minimal support (16\%). Almost half $(48 \%)$ agreed with the statement that mandatory smoking regulations are not needed and that customers should make individual arrangements based on tolerance and courtesy, whereas $11 \%$ were undecided. A majority believed that smoking regulations were the restaurant owner's responsibility. The need for mandatory smoking regulation to provide a smoke-free environment was approved twice as often by non fumare customers (47\% v 23\%).

We analysed factors associated with the preference for mandatory regulations in a multivariate logistic regression model. Lower education (up to high school) (OR 3.2, 95\% CI 1.4 to 7.5 ), visiting the non fumare (OR 2.7, 95\% CI 1.0 to 7.3 ), considering the simultaneous presence of smokers a problem (OR 3.7, 95\% CI 1.8 to 7.9), and knowledge about health effects of secondhand smoke (lung cancer) (OR 2.3, 95\% CI 1.0 to 5.2) were the only independent significant predictors for favouring mandatory regulations.

The analyses of the consumption data show that at any time of our prospective frequency assessment, the number of customers was higher in the non-smoking cafe (on average $+9.5 \%$ in the non fumare). Both the consumption parameters of the past months and the indicators measured during the questionnaire period show slightly but not significantly higher sales in the non-smoking cafe. The alcohol sales were higher in the fumare ( $16.6 \%$ of the drink sales versus $10.8 \%$ in the non fumare), whereas the non fumare had higher sales with coffee/tea and mineral water (non-alcoholic beverages; $p=0.06$ ). The per capita sales pattern did not significantly differ in the two cafes.

In the non fumare, the tips were higher, on each day of the five days, with a daily average of Sw fr 43.00 (95\% CI 39.70 to 46.30 ) in the fumare and Sw fr52.30 (95\% CI 50.60 to 54.10) in the non fumare; thus, tips were on average $22 \%$ higher in the non-smoking cafe $(\mathrm{p}<0.001)$. The tips indexed on a per capita level were only $4 \%$ higher in the non fumare because of the higher number of customers $(\mathrm{p}=0.6)$. Tips expressed in percentage of the total daily sales were on average $12 \%$ $(\mathrm{p}=0.07)$ higher in the fumare than in the non fumare.

Our air quality assessment confirmed differences in air quality in the two cafes, showing a strong influence of smoking on $\mathrm{PM}_{2.5}, \mathrm{VOC}$, and on the content of magnesium, phosphorus, chlorine, potassium, and bromine on $\mathrm{PM}_{25}$. Tables 4 and 5 show the respective results and ratios across the three micro-environments. The fumare had the highest concentrations and the non fumare was similar to the ambient air or slightly higher. 
Table 5 Air pollutant concentration ratios, comparing fumare with non fumare and outdoors, and non fumare with outdoor measurements

\begin{tabular}{|c|c|c|c|}
\hline \multirow[b]{2}{*}{ Air pollution } & \multicolumn{3}{|l|}{ Ratio } \\
\hline & $\begin{array}{l}\text { Fumare/ } \\
\text { non fumare }\end{array}$ & $\begin{array}{l}\text { Fumare/ } \\
\text { outdoor }\end{array}$ & $\begin{array}{l}\text { Non fumare/ } \\
\text { outdoor }\end{array}$ \\
\hline $\begin{array}{l}\mathrm{PM}_{2.5} \\
\text { Elements }\end{array}$ & 4.5 & 15.3 & 3.4 \\
\hline $\mathrm{Mg}$ & 2.7 & 11.3 & 4.0 \\
\hline P & 3.3 & 7.3 & 2.7 \\
\hline $\mathrm{Cl}$ & 24.8 & 50.8 & 2.1 \\
\hline K & 7.2 & 15.3 & 2.2 \\
\hline $\mathrm{Br}$ & 3.0 & 4.3 & 1.5 \\
\hline $\mathrm{NO}_{2}$ & 1.2 & 1.5 & 1.2 \\
\hline \multicolumn{4}{|l|}{ VOC } \\
\hline Benzene & 3.4 & 3.6 & 1.1 \\
\hline Tolvene & 2.3 & 2.2 & 1.0 \\
\hline Ethylbenzene & 2.3 & 2.2 & 0.9 \\
\hline $\mathrm{m} / \mathrm{p}$-xylene & 2.2 & 2.2 & 1.0 \\
\hline o-xylene & 2.0 & 1.9 & 1.0 \\
\hline Styrene & 6.8 & 21.4 & 3.2 \\
\hline
\end{tabular}

Values in bold are significant $(p<0.05)$

Number of measurement periods: $\mathrm{PM}_{2.5}$ and elements: $4 ; \mathrm{NO}_{2}: 3$; VOC: 2 .

\section{DISCUSSION}

We have shown that in the case of offering different smoking policies in otherwise identical cafes, smoking regulation is the key selection criterion among customers that were comparable in all characteristics except their smoking status.

The vast majority of customers in both cafes (86.5\%) were in favour of a landmark departure from the status quo as currently encountered in many countries, indicating nonsmoking facilities should be at least as prevalent as smoking places. An impressive $82 \%$ in the non fumare expressed strong agreement with the statement that smoke-free consumption should be possible in all restaurants. Currently, non-smoking restaurants are very rare in Switzerland. With $91 \%$ wishing to have as many or more non-smoking zones as there are smoking zones, the time may appear ideal to implement mandatory smoking bans in the hospitality business.

Our data show, however, substantial ambivalence regarding regulations. The paradigm of the tobacco industry to call for "tolerance" and "courtesy" ${ }^{8}$ rather than regulation still prevailed in many responses. Even among non fumare customers, only $48 \%$ agreed with mandatory regulations compared to $40 \%$ who did not. Given that the current situation of very limited choice for non-smokers is in fact the consequence of a lack of regulatory vision, our study reveals an interesting paradox, with a call for change on one side, and the contradictory agreement with the tobacco industries "tolerance paradigm", used to stall regulation for decades. ${ }^{18}$

The paradox of the "tolerance paradigm" is also reflected in the large proportion of non-fumare customers of $62 \%$ reporting to "sometimes", "often" or "always" avoiding or leaving places where smoking was allowed. Among non-smokers, this proportion was even higher $(67 \%)$. The only reason for non-smokers choosing the fumare was meeting someone; one may assume that this choice was driven by the preferences of smoking colleagues, thus non-smokers seem to adhere to the call for tolerance. Among smokers, meeting someone was not a reason for choosing the non-smoking cafe. Thus, one may hypothesise that smokers are used to relying on the tolerance of non-smokers, and may not need to compromise on their smoking preference.

We do not know the reasons for the limited support for mandatory policies which would create the (highly welcomed) free choice of smoke-free restaurants and the preference for "private" coping strategies such as avoiding or leaving smoky places. We would need a larger dataset and an expanded questionnaire to address this question. However, one may argue that this ambiguity is a consequence of the smoking friendly environment in which our customers' generation was raised. The normative power of considering smoking a fashionable symbol of youth, glamour, freedom, and adventure, rather than a habit of an addicted minority with adverse health effects on both active and passive smokers, is very strong. ${ }^{16-18}$ It is well known that the industry attempts to make their product attractive to smokers and non-smokers, ${ }^{17}$ which may lead to the high acceptance of the "tolerance and courtesy" strategy of the tobacco industry. It is remarkable that large fractions of non-smokers continue to adhere to the argument of "tolerance" rather than being strong advocates for policies that would support the interests of the vast majority calling for smoke-free opportunities.

People who knew about the health effects of secondary smoke were significantly more likely to favour mandatory policies. This result and the disturbing finding that more than one third of our population, albeit educated well above average, still does not know that secondhand smoke may cause lung cancer, indicates the substantial need for and benefit from information and education, which should preferably reach school children, as well as adults. ${ }^{19} 20$

The analyses of the consumption data are not in line with widespread beliefs. We have no evidence that non-smokers spend less money than the customers in the smoking part. The data suggest that the non-smoking part had more customers during the day, with higher sales in coffee, tea, and mineral water, whereas alcoholic beverage sales were somewhat higher in the fumare. To our knowledge, this is the first study to compare the tipping behaviour of customers in smoking and nonsmoking cafes. In our study, the average non fumare customer left a slightly greater tip than the fumare client. However, relative to the amount of the bills, the fumare client left a greater tip than the non fumare visitor. It is of note that service is officially included in the bill (15\%), thus tips are used as an additional gratuity beyond regular service and are not expected to be some specified percentage of total expenses. Therefore, one may expect that the higher the total expense, the lower the relative gratuity. Socioeconomic status may also influence the tipping. Although educational level was very similarly distributed across the two customer groups, confounding cannot strictly be ruled out. However, what may particularly count for the waiter are the total amount and the amount received per customer. Our data suggest that during the daytime waiters should be better off working in the non-smoking part. Nonetheless, the anecdotal belief of waiters reflect the opposite notion that better tips will be received in the smoking part. This may either illustrate discrepancies between widespread beliefs, well supported by tobacco industry claims, ${ }^{56}$ and reality or it may partly be due to the waiters' evening and night time experience. We did not investigate these shifts, but customers, consumption, and tipping patterns could strongly change at these times where the choices of drinks differ, as does the character of the business-that is, being more a bar than a cafe.

\section{Study limitations}

Major limitations of our study relate to the small and the nonrepresentative sample. With a larger sample, confounding caused by co-factors such as socioeconomic status, knowledge, and beliefs could be addressed more rigorously. A larger sample would also allow investigation of individual determinants of the prevalent discrepancy between the preference of smoke-free environments on one side, and the hesitation to support clear ordinances that would bring the freedom of smoke-free choices. Our study population from the "Unternehmen Mitte" and the findings may be representative for 


\section{What this paper adds}

The hospitality business, lobbied by the tobacco industry, claims that smoking bans reduce profits. Although shown not to be true if bans apply to whole cities or regions, the issue has not been investigated in an unregulated market as it currently exists in many European countries. This study used a unique experimental setting of equal choice for a smoking and non-smoking cafe to investigate the substance of these claims and beliefs.

The study found no evidence of economic disadvantage of a "free choice" non-smoking offer. In contrast, a majority have left or avoided smoking places in the past, and wanted at least an equal amount of smoke-free zones. The non-smoking part had equal or better economic performance, and tips tended to be higher than in the smoking part. Strategies need to be developed to change the observed customer ambivalence, calling for a major shift towards smoke-free environments while being reluctant to accept mandatory regulations.

a young (average age 34 years), urban population, with above average education, ${ }^{21}$ visiting cafes during daytime. Generalisations beyond this group may not be appropriate. Still, it is important to note that despite this restriction, the study represents a substantial fraction of the population and consumer time; thus, the innovative concept of "fumare non fumare" may be successfully copied, regardless of the regulatory policies. Given the low key regulatory activities in Switzerland, which continue to be dominated by the tobacco industry and paradoxical opinions by the public, hospitality business owners may be well advised to offer non-smoking facilities in the near future rather than waiting until the adoption of clear regulations. New alliances are needed between the hospitality business and public health professionals. The former should be aware that according to our findings, the tobacco industry, although a longstanding partner, is a poor advocate of the interests of the hospitality business customers.

Our air pollutant concentrations' confirm previous findings $\mathrm{s}^{22}$ which indicated that smoking related exposures among waiters can be high. ${ }^{23}{ }^{24}$ In our study, the smoking part has a separate ventilation system, and the connecting doors to the hallway were often open, so air quality differences between the two parts may be less pronounced. The high health risk to exposed workers leads to costs for the business owner, ${ }^{25}$ indicating a further economic argument why business owners should opt for smoke-free facilities. According to a new report there are no safe levels of exposure to tobacco smoke and adverse effects can already be seen at low levels of exposure; secondhand smoke-considered a human carcinogen-increases the risk of lung cancer by some 20-30\% and the risk of coronary heart disease by $25-35 \%{ }^{22} 2627$

\section{Conclusion}

We conclude that our findings underline the need to inform the public about the health effects of environmental tobacco smoke and that policymakers should reflect the preferences of the large majority, who desire a strong move towards more non-smoking places. However, the causes of their paradoxical reluctance towards regulations need to be carefully addressed in order to develop well supported regulatory strategies. Otherwise, the lobbying of the tobacco industry for "tolerance" and "courtesy" will continue to be successful and stall the promotion of smoke-free environments. Given free choice, the vast majority of customers enthusiastically welcome nonsmoking cafes, where they spend at least as much as in smoking cafes.

\section{ACKNOWLEDGEMENTS}

The authors would like to acknowledge the contribution of all those that made this study possible. Foremost we thank the Lung Association Zürich (Lungenliga) for funding and Daniel Häni from the "Unternehmen Mitte" for letting us conduct this study. Many thanks to Hans Weniger for the lab work on $\mathrm{PM}_{2.5}$ and to Carbotech AG and Passam AG for the analysis of VOC and $\mathrm{NO}_{2}$. At the time of this study, the first author was recipient of a National Science Foundation Advanced Scientist Fellowship (\#3233-048922.96/ 1).

Conflict of interest: This study was conducted without conflict of interests. The Zurich Lung Association funded the project but had no influence on study design, data collection, analysis, interpretation, and writing the report. The "Unternehmen Mitte" made no restrictions on the use of their facilities, data analysis or interpretation.

\section{Authors' affiliations}

*N Künzli, †P Mazzoletti, †M Adam, *T Götschi, P Mathys, Institute of Social and Preventive Medicine, University Basel, Switzerland C Monn, Federal Institute of Technology, Zürich, Switzerland O Brändli, Zürcher Höhenklinik Wald, Wald, Switzerland

*Also Keck School of Medicine, University of Southern California, Los Angeles, USA

†Also Federal Institute of Technology, Zürich, Switzerland

\section{REFERENCES}

1 Lee CY, Glantz SA. The tobacco industry's successful efforts to control tobacco policy making in Switzerland. 2001. URL: http:// www.library.ucsf.edu/tobacco/swiss

2 Swiss Federal Tobacco Commission, until 1996 (Eidgenössische Tabakkommission), after 1996 "Federal Commission for Tobacco Prevention" (Eidgenössische Kommission für Tabakprävention). URL: http://www.bag.admin.ch/dienste/medien/1998/d/98060408.htm

3 World Health Organization. The tobacco free initiative. WHO, The Tobacco Atlas. URL: http://www5.who.int/tobacco/repository/stp84/ table-a.pdf

4 World Health Organization, Regional Office for Europe. The European tobacco control report: review of implementation of the third action plan for a tobacco free Europe 1997-2001, Copenhagen, 2001.

5 Americans for Nonsmokers' Rights and American Nonsmokers' Rights Foundation. Berkeley California. URL: http:// www.no-smoke.org/index.html

6 University of California San Francisco. Tobacco scam. San Francisco: UCSF. URL: http://www.tobaccoscam.ucsf.edu/

7 Arbeitsgemeinschaft Tabakprävention Schweiz. URL: Bern. http://www.at-schweiz.ch/tabakindustrie/

8 Dearlove JV, Bialous SA, Glantz SA. Tobacco industry manipulation of the hospitality industry to maintain smoking in public places. Tobacco Control 2002;11:94-104.

9 Glantz SA, Smith LR. The effect of ordinances requiring smoke-free restaurants and bars on revenue: a follow-up. Am J Public Health 1997;87: 1687-93.

10 Bartosch WJ, Pope GC. Economic effect of restaurant smoking restrictions on restaurant business in Massachusetts, 1992 to 1998. Tobacco Control 2002; 11 (suppl II):ii38-42.

11 Centers for Disease Control and Prevention. Assessment of the impact of a $100 \%$ smoke-free ordinance on restaurant sales-West Lake Hills, Texas, 1992-1994. JAMA 1995;274:206-8.

12 Koistinen KJ, Kousa A, Tenhola V, et al. Fine particle (PM2.5) measurement methodology, quality assurance procedures, and pilot results of the EXPOLIS study. J Air Waste Manag Assoc 1999;49:1212-20.

13 Hazenkamp-von Arx ME, Götschi Fellmann T, Oglesby L, et al. PM2.5 Assessment in 21 European Study Centers of ECRHS II, Method and first Winter Results, 2002:6.

14 Mathys P, Stern WB, Oglesby L, et al. Elemental analysis of airborne particulate matter by ED-XRF within the European EXPOLIS study. ICP Information Newsletter 2001;27:190-5.

15 Mazzoletti P, Adam M. Fumare non fumare: Eine Raucher Nichtraucher Studie in einer urbanen Fasler Kaffee-Bar. (Master-Thesis). Swiss Federal Institute of Technology, Zurich, 2002.

16 Barbeau EM, DeJong W, Brugge DM, et al. Does cigarette print advertising adhere to the Tobacco Institute's voluntary advertising and promotion code? An assessment. J Public Health Policy 1998; 19:473-88.

17 Pollay RW. Targeting youth and concerned smokers: evidence from Canadian tobacco industry documents. Tobacco Control 2000;9:136-47.

18 Hong T, Cody M. Presence of pro-tobacco messages on the web. $J$ Health Commun 2002;7:267-72. 
19 Eckhardt L, Woodruff SI, Elder JP. Related effectiveness of continued, lapsed, and delayed smoking prevention intervention in senior high school students. Am J Health Promot 1997;11:418-21.

20 Wakefield M, Chaloupka F. Effectiveness of comprehensive tobacco control programmes in reducing teenage smoking in the USA. Tobacco Control 2000:9: 177-86.

21 Bundesamt für Statistik. Bildung und Wissenschaft. Bildungsstand 2000. Schweiz. URL: http://www.statistik.admin.ch/stat_ch/ber15/ dufr 15.htm

22 US Environmental Protection Agency. Respiratory health effects of passive smoking: lung cancer and other disorders. Washington DC: US Environmental Protection Agency, 1997.

23 Siegel M. Involuntary smoking in the cafe workplace. A review of employee exposure and health effects. JAMA 1993:270:490-3.
24 Eisner MD, Smith AK, Blanc PD. Bartenders' respiratory health after establishment of smoke-free bars and taverns. JAMA 1998;280:1909_ 14.

25 McGhee SM, Adab P, Hedley AJ, et al. Passive smoking at work: the short-term cost. J Epidemiol Community Health 2000;54:673-6.

26 British Medical Association. Board of Science and Education \& Tobacco Control Resource Centre. Towards smoke-free public places. London: BMA, November 2002.

27 World Health Organization. International Agency for Research on Cancer. Monograph on the evaluation of carcinogenic risks to humans. Volume 83. Tobacco smoke and involuntary smoking. Lyon: WHO IARC (in press). Lyon. Summary available at: http://monographs.iarc.fr/ htdocs/indexes/vol83index.htm

\section{The Lighter Side}

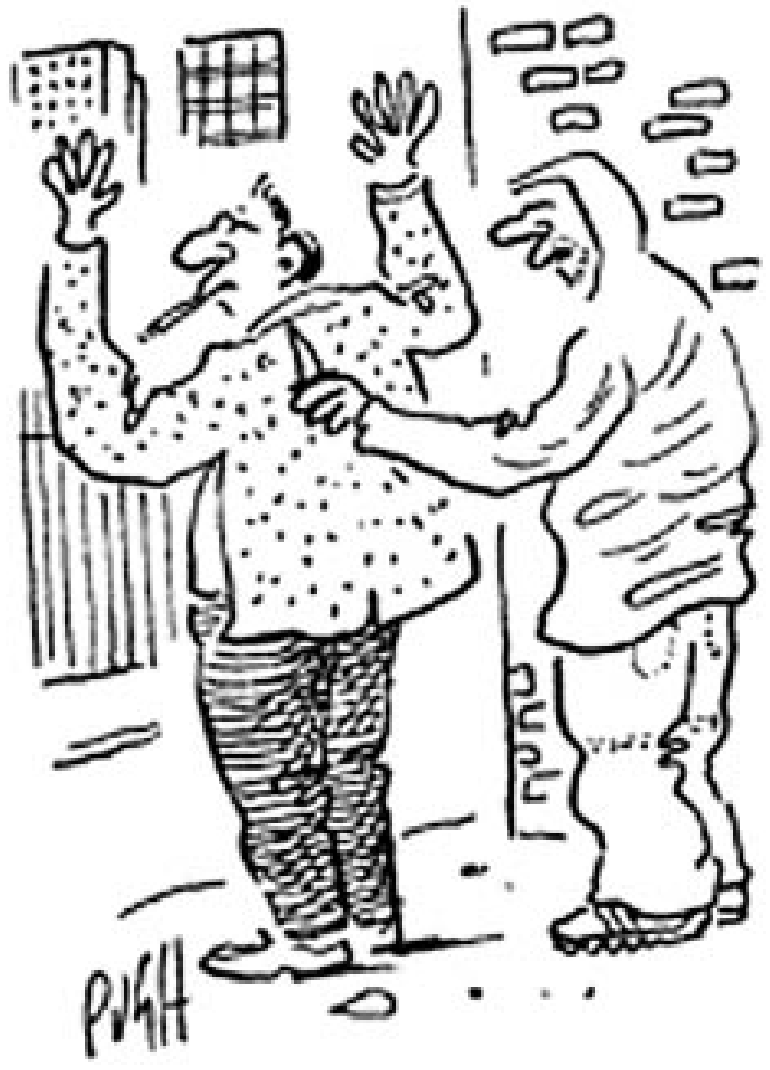

\section{"Not your mobile phone, your cigarettes"}

(C) Copyright Jonathan Pugh/The Times, 10th April, 2003 